Berkala Ilmu Perpustakaan dan Informasi, Vol. 14, No. 1, Juni 2018, Hal. 76-86 DOI: 10.22146/bip.28943

ISSN 1693-7740 (Print), ISSN 2477-0361 (Online)

Tersedia online di https://jurnal.ugm.ac.id/bip

\title{
Analisis dan perancangan desain sistem informasi perpustakaan sekolah berdasarkan kebutuhan sistem
}

\author{
Nurul Alifah Rahmawati ${ }^{1}$ dan Arif Cahyo Bachtiar ${ }^{1}$ \\ ${ }^{1}$ Pascasarjana, Universitas Islam Negeri Sunan Kalijaga Yogyakarta \\ Email:nurulalifah301@yahoo.com
}

Naskah diterima: 12 Oktober 2017, direvisi: 6 Maret 2018, disetujui: 24 April 2018

\begin{abstract}
ABSTRAK
Pendahuluan. Perpustakaan sekolah sebagai bagian dari lembaga pendidikan dituntut untuk menyediakan segala sumber informasi yang dibutuhkan dalam proses belajar mengajar. Untuk meningkatkan layanan sumber informasi di perpustakaan dibutuhkan sistem informasi agar pelayanan lebih efektif dan efisien.

Metode penelitian. Metode penelitian yang digunakan yaitu metode pengembangan sistem yang berarti menyusun sistem yang baru atau mengembangkan sistem yang telah ada di perpustakaan sekolah.

Metode Analisis.Perancangan sistem informasi perpustakaan sekolah didasarkan pada analisis kebutuhan untuk mengurangi kesulitan-kesulitan yang terjadi pada layanan perpustakaan.

Hasil dan Pembahasan.Rancangan sistem informasi perpustakaan sekolah dibuat lebih sederhana daripada perpustakaan perguruan tinggi maupun perpustakaan daerah yaitu berdasarkan pada layanan sirkulasi meliputi peminjaman dan pengembalian serta laporan denda. Sistem informasi perpustakaan sekolah yang dibuat ini dirancang dengan bahasa pemrograman phpMyAdmin dan basis data SQL. Tahapan yang dilakukan antara lain dengan memasukkan data koleksi, data anggota, cetak kartu anggota, cetak kartu bebas pustaka, transaksi peminjaman dan pengembalian hingga pelaporan-pelaporan data termasuk laporan denda. Perancangan yang dilakukan untuk membuat sistem informasi perpustakaan sekolah ini meliputi perancangan sistem hingga perancangan antar muka untuk memudahkan pengguna maupun pustakawan dalam mengelola perpustakaan sekolah.

Kesimpulan dan Saran. Diharapkan dengan adanya perancangan sistem yang sederhana, setiap perpustakaan sekolah dapat membuat sendiri sistem informasi untuk perpustakaannya agar pelayanan di perpustakaan semakin efektif dan efisien.
\end{abstract}

Kata kunci: Perancangan, Sistem Informasi, Perpustakaan Sekolah.

\section{ABSTRACT}

Introduction.School libraries as part of the educational institution are required to provide all the necessary information resources to support learning process. A reliable library system is needed to improve the library services.

Data Collection Method.Theresearch method used was observation to developa new system and improve an existing one.

Data Analysis.The design of the school library information system is based on "need analysis" to tackle problems occur in library services.

Results and Discussions. The design of school library information systems is made simpler than University library or regional library or even archive management that are based on circulation services, including lending and returning and fines. The school library information system is designed by using phpMyAdmin programming language and SQL database. The steps taken include inputting data collections, membership data, membercard printing, library free printing, lending and returning transactions and data reporting, including fines. The design undertaken to make the school library information system includes the design of the interface system design to facilitate users and librarians in managing the school library. 
Conclusions and recommendations. With the simple system design, it is expected that school libraries can create their own information system so that the service can be more effective and efficient.

Keywords: Design, Information System, School Library.

\section{A. PENDAHULUAN}

Sistem informasi telah memberikan nilai tambah baik dalam proses, produksi, manajemen, kualitas, pengambilan keputusan, pemecahan masalah hingga keunggulan kompetitif yang tentunya sangat bermanfaat untuk kegiatan dalam suatu lembaga (Kadir, 2009). Peranan sistem informasi dalam berbagai aspek termasuk perpustakaan membuatnya memiliki keunggulan kompetitif. Adanya sistem informasi ini tidak hanya memberikan manfaat bagi perpustakaan itu sendiri, namun juga bermanfaat bagi penggunanya. Perpustakaan sebagai bagian dari lembaga pendidikan turut serta dalam meningkatkan ilmu pengetahuan bagi para siswanya. Hal ini dikarenakan, perpustakaan menyediakan segala sumber informasi yang dibutuhkan dalam proses pembelajaran di sekolah. Oleh karena itu, pemanfaatan sistem informasi di perpustakaan menjadi sesuatu yang sangat diperlukan untuk menunjang proses belajar mengajar di sekolah.

Pemanfaatan sistem informasi dapat meningkatkan kualitas layananbaik kecepatan maupun kualitas informasi yang diberikan untuk mengelola atau menjalankan operasional perpustakaan (Dana, Samosir \& Widiyasa, 2015). Apabila dalam pelaksanaannya, perpustakaan belum menerapkan sistem informasi berbasis komputer, dalam hal ini masih menggunakan manual baik dalam pengolahan maupun pelayanan, maka akan sulit meningkatkan ilmu pengetahuan bagi siswanya. Pengolahan perpustakaan menggunakan sistem manual membutuhkan waktu yang relatif lama dan dapat mengakibatkan koleksi terlambat untuk dilayankan kepada pemustaka yang membutuhkan. Selain itu pelayanan juga akan lebih lama dibandingkan jika sudah tersistem dalam komputer. Hal ini yang menjadikan pentingnya menerapkan sistem informasi untuk perpustakaan. Sistem informasi perpustakaan dapat digunakan untuk memecahkan masalah dalam pengolahan maupun pelayanan perpustakaan.

Penggunaansistem otomasi perpustakaan sudah menjadi keharusan bagi perpustakaan dalam upaya meningkatkan layanan yang berkualitas bagi penggunanya. Semakin mudahnya akses terhadap internet yang dapat digunakan untuk keperluan komunikasi dan informasi oleh masyarakat kapan saja dan di manapun mereka berada menjadi alasan untuk mengembangkan sistem perpustakaan,sehingga informasi yang dimiliki oleh suatu perpustakaan dapat dengan mudah disebarluaskan kepada masyarakat (Rahmawati, 2015).

Beberapa literatur atau artikel yang dapat digunakan sebagai landasan teori dalam penelitian ini, diantaranya penelitian yang dilakukan oleh Emy Budi Susilowati dan Bambang Eka Purnama yang berjudul "Analisis dan Perancangan Sistem Informasi Pasien Rumah Sakit Umum Nirmala Suri Sukoharjo" (Susilowati, 2017). Penelitian selanjutnya dilakukan oleh Fajar Nugraha berjudul "Analisis dan Perancangan Sistem informasi Perpustakaan" (Nugraha, 2014). Selanjutnya penelitian juga dilakukan oleh Fitri Yanti, dkk yang berjudul "Perancangan Sistem Informasi Perpustakaan Berbasis WEB dan SMS Gateway di SMA Negeri 3 Padang" (Yanti, 2014). Dari beberapa artikel tersebut, dapat disimpulkan bahwa landasan teori dalam analisis dan perancangan sistem informasi meliputi konsep dasar sistem dan informasi serta analisis sistem dan perancangannya.

Layanan pengadaan koleksi, penelusuran informasi, pengolahan bibliografi, keanggotaan, sirkulasi, pelaporan, inventarisasi koleksi, serta pengelolaan kontrol terbitan berseri merupakan beberapa layanan di perpustakaan yang dapat diintegrasikan dengan menggunakan sistem otomasi perpustakaan di dalamnya (Azwar, 2015). Namun sayangnya hanya sebagian kecil perpustakaan di Indonesia, 
khususnya perpustakaan sekolah yang telah menerapkan sistem otomasi dalam melakukan layanan di perpustakaannya.

Sistem informasi perpustakaan sekolah lebih sederhana dari pada sistem informasi perpustakaan yang lain. Hal ini dikarenakan, pengguna dalam perpustakaan sekolah belum begitu kritis dalam pemikirannya. Sistem informasi yang dibutuhkan cukup meliputi pendataan, transaksi berupa peminjaman dan pengembalian serta laporan. Dengan membuat analisis dan rancangan sistem perpustakaan sekolah yang sederhana ini, pelayanan perpustakaan akan lebih meningkat. Berdasarkan latar belakang tersebut, rumusan masalah dalam artikel ini yaitu bagaimanakah analisis dan rancangan sistem informasi perpustakaan sekolah berdasarkan kebutuhan sistem?

\section{B. TINJAUAN PUSTAKA \\ 1. Konsep Dasar Sistem}

Konsep dasar sistem memiliki banyak perbedaan definisi menurut para ahlinya. Definisi mengenai sistem berdasarkan pendekatan sistem terdiri dari sistem yang menekankan pada prosedur dan sistem yang menekankan pada elemennya. Pendekatan sistem yang menekankan pada prosedurnya didefinisikan oleh Jerry Fitz Gerald. Menurutnya, sistem dapat didefinisikan sebagai suatu jaringan kerja yang terdiri dari prosedurprosedur yang saling berhubungan, kemudian berkumpul bersama-sama untuk melakukan atau menyelesaikan kegiatan dan mencapai suatu sasaran tertentu (Jogiyanto, 2000). Sedangkan sistem yang menekankan pada elemennya didefinisikan oleh Robert G. Murdick, yaitu sistem terdiri dari elemenelemen yang saling terintegrasi dengan tujuan yang sama untuk mencapai sasaran yang diharapkan (Ladjamudin, 2013). Jadi berdasarkan pendekatan sistem dapat ditarik kesimpulan bahwa sistem merupakan elemenelemen atau prosedur-prosedur yang disusun serta terintegrasi dengan tujuan bersama untuk mencapai sasaran tertentu.

Suatu sistem informasi memiliki karakteristik atau sifat-sifat tertentu antara lain komponen sistem, batasan, lingkungan luar sistem, penghubung, input, output, pengolahan serta sasaran dan tujuan sistem (Ladjamudin, 2013). Karakteristik atau sifat-sifat sistem ini digunakan untuk mencapai tujuan dari sistem tersebut.

\section{Konsep Dasar Informasi}

Konsep dasar informasi menurut Gordon B. Darwis (1985) yaitu bahwa informasi sebagai sebuah data yang telah dilakukan pengolahan manjadi suatu bentuk yang lebih berarti serta berguna bagi penggunanya dalam pengambilan keputusan baik untuk masa kini atau yang akan datang (Ladjamudin, 2013). Manfaat dari adanya informasi ini yaitu untuk mengurangi kesalahan dalam mengambil suatu keputusan. Informasi digunakan oleh seluruh pengguna artinya tidak hanya digunakan oleh satu orang saja. Informasi yang bernilai bagi seseorang adalah informasi yang bermanfaat bagi dirinya. Meskipun ditujukan untuk semua orang, namun jika informasi tersebut tidak dibutuhkan oleh orang tersebut maka informasi itu tidaklah bernilai atau bermanfaat, artinya informasi tersebut bisa dikatakan sebagai sampah.

\section{Sistem Informasi Perpustakaan}

Sistem informasi merupakan elemenelemen yang terdapat dalam suatu organisasi yang didalamnya terdiri dari sekelompok orang, media, teknologi, prosedur-prosedur serta pengendalian yang dapat digunakan untuk berkomunikasi, transaksi, serta menyediakan informasi dalam pengambilan suatu keputusan. (Paryati \& Yosef, 2008).Sedangkan menurut Lasa, sistem informasi merupakan sekumpulan aturan yang membentuk sistem dalam menyajikan data yang memiliki arti/meaningful dan daya guna/useful (Lasa, 2009). Berdasarkan definisi tersebut, jika ditarik kedalam definisi sistem informasi perpustakaan, maka definisi tersebut akan dihubungkan dengan pemenuhan kebutuhan pemustaka. Jadi sistem informasi perpustakaan dapat didefinisikan sebagai seperangkat aturan atau elemen yang berada dalam organisasi yang digunakan untuk pemenuhan kebutuhan yang ada di perpustakaan. 
Sistem informasi terdiri dari lima komponen yaituhardware (perangkat keras), software (perangkat lunak), data, prosedur, dan manusia (Ladjamudin, 2013).

a) Hardware (perangkat keras), mencakup berbagai peralatan fisik seperti komputer dan printer.

b) Software (perangkat lunak), berupa perintah-perintah tertentu yang ditujukan untuk memerintahkan komponen melaksanakan tugasnya.

c) Data, merupakan komponen paling dasar atau masih mentah dari suatu informasi yang akan diproses lebih lanjut agar dapat berarti dan dapat menghasilkan informasi.

d) Prosedur, merupakan aturan-aturan yang digunakan untuk menghubungkan berbagai macam perintah dan data untuk menentukan rancangan dan penggunaan sistem informasi.

e) Manusia, merupakan pelaksana yaitu mereka yang terlibat dalam kegiatan sistem informasi seperti operator, pemimpin dan sebagainya.

\section{Perpustakaan Sekolah}

Perpustakaan sekolah merupakan bahan pustaka cetak maupun noncetak yang telah terorganisir secara sistematis dalam suatu ruangan yang digunakan untuk membantu para siswa dan guru dalam menunjang proses pembelajaran disekolah (Bafadal, 2006). Perpustakaan sekolah menjadi salah satu bagian penting dalam program sekolah secara keseluruhan, karena perpustakaan sekolah juga turut menentukan keberhasilan proses pendidikan dan pembelajaran bagi para siswanya (Darmono, 2001).

Dari beberapa pengertian tersebut dapat dipahami bahwa perpustakaan sekolah merupakan bagian dari program sekolah yang terorganisir secara sistematis sehingga dapat membantu keberhasilan proses belajar mengajar disekolah. Untuk memaksimalkan perpustakaan sebagai sarana keberhasilan sekolah perpustakaan memanfaatkan teknologi informasi sebagai sarana penunjang tugas dan fungsinya. Teknologi merupakan salah satu pendukung perpustakaan untuk memberikan layanan yang lebih baik bagi pemustaka. Dengan demikian, sudah jelas bahwa perpustakaan sekolah membutuhkan teknologi informasi untuk meningkatkan layanan bagi pemustakanya.

\section{Kebutuhan Sistem Informasi pada Perpustakaan Sekolah}

Kebutuhan sistem informasi setiap perpustakaan berbeda-beda. Perpustakaan perguruan tinggi jelas memiliki kebutuhan sistem yang lebih lengkap dan kompleks dibandingkan kebutuhan sistem informasi pada perpustakaan sekolah yang lebih sederhana. Hal ini dikarenakan pengguna pada masing-masing perpustakaan sangatlah berbeda. Pengguna pada perpustakaan perguruan tinggi terdiri dari mahasiswa, dosen dan peneliti yang mempunyai tingkat keilmuan yang lebih tinggi dibandingkan pengguna pada perpustakaan sekolah. Oleh karena itu, teknologi informasi yang digunakan oleh perpustakaan perguruan tinggi bukanlah teknologi yang masih sederhana.

Hal ini berbeda dengan kebutuhan sistem informasi pada perpustakaan sekolah yang masih sederhana. Meskipun hal ini masih sederhana, namun tetap harus mencangkup komponen sistem yang paling penting meliputi hardware, software dan brainware. Untuk memenuhi komponen tersebut, perlu diketahui jenis layanan yang ada di perpustakan sekolah.

Jenis layanan perpustakaan sekolah pada umumnya meliputi (Darmono, 2001):

a) Layanan Sirkulalsi

Layanan sirkulasi merupakan kegiatan melayani peminjaman dan pengembalian bahan pustaka.Pelayanan sirkulasi mempunyai tugas antara lain peminjaman, pengembalian, pemberian sanksi, penagihan, pemberian informasi peraturan dan tata tertib perpustakaan, serta bebas pustaka.

b) Layanan Referensi

Bagian layanan referensi mempunyai tugas untuk memberikan informasi atau mengarahkan pemustaka agar dapat menemukan koleksi referensi secara efektif dan efisien. Koleksi referensi merupakan 
koleksi yang tidak dapat dipinjam karena sifatnya sebagai buku petunjuk. Misalnya, kamus, ensiklopedia, bibliografi dll.

c) Layanan Bimbingan Pemanfatan Perpustakaan.

Bimbingan pemanfaatan perpustakaan diberikan kepada anggota baru. Mereka akan mendapatkan penjelasan tentang berbagai informasi mengenai perpustakaan, meliputi pengenalan lokasi perpustakaan, peraturan serta tata tertib perpustakaan, layanan yang disediakan, jenis koleksi, cara penelusuran informasi serta ruang baca dan sirkulasi koleksi.

Berdasarkan jenis layanan yang terdapat di perpustakaan sekolah, dapat diketahui bahwa kebutuhan sistem informasi yang paling penting yaitu pada layanan sirkulasi berupa peminjaman dan pengembalian. Oleh karena itu dibutuhkan sistem yang dapat membantu dalam meningkatkan layanan sirkulasi tersebut.

\section{METODE PENELITIAN}

Metode penelitian yang digunakan yaitu metode pengembangan sistem. Metode pengembangan sistem secara umum diartikan sebagai urutan langkah-langkah yang terstruktur untuk mengembangkan sebuah sistem informasi berbasis komputer. Metode pengembangan sistem juga dapat berarti menyusun suatu sistem yang baru untuk menggantikan sistem yang lama secara keseluruhan atau mengembangkan sistem yang telah ada (Taufiq, 2013). Metode pengembangan sistem yang digunakan dalam penelitian ini yaitu System Development Life Cycleatau SDLC.Metode SDLC ini memiliki tahapan-tahapan dan langkah-langkah meliputi perencanaan, analisis, perancangan sistem, implementasi hingga pemeliharaansistem informasi. Namun, dalam artikel ini tahapan yang dilakukan hanya sampai perancangan desain sistem baik perancangan untuk isi maupun desain antar muka.

\section{HASILDAN PEMBAHASAN \\ 1. Analisis Masalah}

Analisis masalah digunakan untuk mengetahui permasalahan yang terjadi di perpustakaan sekolah terutama pada layanan sirkulasi yang meliputi peminjaman, pengembalian, pendataan keanggotaan, pelaporan data peminjaman, dan denda.

\section{Analisis Kebutuhan Sistem}

Tujuan dari analisis kebutuhan sistem yaitu mengurangi kesulitan yang terjadi pada proses pengolahan data dan proses pelaporan data di perpustakaan sekolah, serta meningkatkan layanan yang lebih baik bagi pemustaka.

Kebutuhan sistem informasi perpustakaan sekolah lebih sederhana dibandingkan dengan perpustakaan yang lain, namun tetap harus mencangkup komponen sistem yang meliputi hardware, software dan brainware. Kebutuhan sistem informasi perpustakaan sekolah yang paling penting yaitu pada layanan sirkulasi atau transaksi. Oleh karena itu dibutuhkan rancangan sistem yang dapat membantu dan meningkatkan layanan di perpustakaan sekolah.

\section{Analisis Kelayakan Sistem}

Analisis kelayakan sistem dilakukan untuk mengetahui apakah sistem yang baru lebih baik dari pada sistem yang lama. Hal ini meliputi kelayakan teknologi, hukum, operasional, dan kelayakan ekonomi.

\section{Analisis Biaya dan Manfaat}

Analisis biaya dan manfaat dilakukan untuk mengetahui apakah sistem yang dibuat layak atau tidak untuk digunakan. Biaya yang dibutuhkan meliputi biaya pembuatan sistem, biaya perangkat yang dibutuhkan, dan juga biaya perawatan sistem.

\section{Perancangan Sistem}

\section{a) Diagram Konteks}

Diagram konteks merupakan suatu bentuk diagram yang menggambarkan proses serta ruang lingkup kerja suatu sistem (Ladjamudin, 2013). Berdasarkan hasil analisis kebutuhan sistem informasi di perpustakaan sekolah, maka perlu melakukan perancangan sistem informasi perpustakaan untuk meningkatkan pelayanan sirkulasi dan keanggotaan perpustakaan. Diagram konteks ini menggambarkan hubungan dan interaksi antara sistem informasi 
perpustakaan dengan komponen luar sistem. Desain sistem diagram konteks digambarkan pada Gambar 1.

Diagram konteks diatas menggambarkan adanya interaksi antara sistem informasi perpustakaan dengan komponen luar sistem yang berupa anggota dan pustakawan. Interaksi antara anggota dengan sistem yaitu adanya informasi mengenai data anggota, data peminjaman, data pengembalian serta data denda yang dimasukkan kedalam sistem informasi perpustakaan. Sedangkan timbal balik dari sistem kepada anggota yaitu adanya kartu anggota dan surat bebas pustaka. Selanjutnya interaksi antara pustakawan dengan sistem selain memasukkan data anggota yang diperoleh dari setiap anggota perpustakaan, juga memasukkan data koleksi. Hasil dari sistem kepada pustakawan yaitu berupa laporanlaporan terkait data tersebut.

Sistem informasi perpustakaan sekolah ini menggunakan Php sebagai bahasa pemrogramannya dan MySQL sebagai komponen basis datanya. PhpMyAdmin memiliki keunggulan dibandingkan dengan bahasa pemrograman opensource yang lain. Php ini sangat sederhana dan mudah untuk dimengerti atau dipahami sehingga cocok digunakan untuk seorang pemula maupun yang sudah ahli. Selain itu karena PhpMyAdmin ini juga opensource, Php juga banyak digunakan pada sistem operasi (Windows, Linux, Unix dan lain-lain). Php juga mendukung basis data SQL dan yang lainnya. Sedangkan penggunaan basis data SQL ini karena secara global MySQL terkenal menjadi manajemen basis data yang handal dan paling aman. Selain itu juga dapat didukung oleh sebagian besar sistem operasi dan bahasa pemrograman.

\section{b) Data Flow Diagram(DFD)}

Data flow diagram (DFD) atau diagram aliran data merupakan model dari sistem untuk menggambarkan pembagian sistem ke modul yang lebih kecil (Ladjamudin, 2013). DFD ini menggambarkan aliran data dari masukan yaitu data dari anggota maupun perpustakaan yang di masukkan oleh pustakawan sebagai pengguna kedalam sistem, penyimpanan data hingga proses keluaran berupa laporan data-data terkait. Diagram ini akan menjelaskan alur data yang terdapat dari sistem informasi perpustakaan sekolah. Mulai dari input data koleksi maupun data anggota. Lalu dengan data anggota dan data koleksi tersebut dapat dilanjutkan untuk memproses peminjaman koleksi yang diambil dari data koleksi dan data anggota. Akhirnya, akan didapatkan data berupa laporan. Laporan tersebut terdiri dari koleksi, anggota, data laporan peminjaman,serta data pengembalian. Data flow diagram level-0 sistem informasi perpustakaan sekolah adalah pada Gambar 2.

Diagram diatas menggambarkan aliran data antara dalam dan luar sistem. Dimulai dari masukan berupa data-data anggota dan koleksi, kemudian transaksi meliputi peminjaman dan pengembalian hingga keluaran yang menghasilkan laporan-laporan data terkait. Laporan-laporan data tersebut akan dicetak oleh pustakawan sebagai hasil keluaran dari sistem informasi perpustakaan sekolah tersebut.

\section{Struktur Tabel}

Struktur tabel dalam rancangan sistem informasi perpustakaan sekolah ini disajikan dalam bahasa pemrograman phpMyAdmin dan basis data SQL. Adapun rancangan struktur tabelnya adalah sebagai berikut:

1) Tabel Anggota

Tampilan struktur Table Anggota pada basis data SQL dapat dilihat pada Tabel 1.

Dalam Tabel 1 tersebut terdapat 5 field, yaitu field Id_anggota menggunakan tipe data char dengan panjang 10 karakter, Field Nama mengunakan tipe data varchar dengan panjang 20 karakter. Field Kelas menggunakan tipe data varchar dengan panjang 5 karakter. Field TTL menggunakan tipe data date, dan field Alamat menggunakan tipe data varchar dengan panjang 30 karakter.

\section{2) Tabel Koleksi}

Tampilan struktur Tabel Koleksi pada basis data SQL dapat dilihat pada Tabel 2.

Dalam Tabel 2 tersebut terdapat 6 field, yaitu field Id buku menggunakan tipe data char dengan panjang 10 karakter, Field Judul 
mengunakan tipe data varchar dengan panjang 30 karakter. Field Pengarang menggunakan tipe data varchar dengan panjang 20 karakter. Field Penerbit menggunakan tipe data varchar dengan panjang 20 karakter, Field Tahun_Terbit menggunakan tipe data integer dengan panjang 11 karakter. Serta field ISBN menggunkan tipe data char dengan panjang 13 karakter.

3) Tabel Peminjaman

Tampilan struktur Tabel Peminjaman pada basis data SQL dapat dilihat pada Tabel 3.

Dalam Tabel 3 tersebut terdapat 5 field, yaitu field Id Anggota menggunakan tipe data char dengan panjang 10 karakter, field ID_Buku mengunakan tipe data char dengan panjang 10 karakter. Field Tanggal_Peminjaman menggunakan tipe data date. Field Tanggal_Kembali menggunakan tipe data date, Serta field Kode_Pinjam menggunkan tipe data char dengan panjang 10 karakter.

4) Tabel Pengembalian

Tampilan struktur Tabel Pengembalian pada basis data SQL dapat dilihat pada Tabel 4.

Dalam Tabel 4 tersebut terdapat 6 field, yaitu field Id Anggota menggunakan tipe data char dengan panjang 10 karakter, field ID_Buku mengunakan tipe data char dengan panjang 10 karakter. Field Tanggal_Peminjaman menggunakan tipe data date. Field Tanggal_Kembali menggunakan tipe data date, field Kode_Pinjam menggunkan tipe data char dengan panjang 10 karakter, serta field Kode_Kembali menggunakan tipe data char dengan panjang 10 karakter.

\section{5) Tabel Denda}

Tampilan struktur Tabel Denda pada basis data SQL dapat dilihat pada Tabel 5.

Dalam Tabel 5 tersebut terdapat 4 field, yaitu field No_Denda menggunakan tipe data char dengan panjang 10 karakter, field Kode_Pinjam mengunakan tipe data char dengan panjang 10 karakter, field Kode_Kembali menggunakan tipe data char dengan panjang 10 karakter, serta field Jumlah Denda menggunakan tipe data integer dengan panjang 10 karakter.

\section{Relasi Tabel}

Relasi tabel ini menggambarkan hubungan antara struktur tabel-tabel yang ada pada sistem informasi perpustakaan sekolah tersebut. Hubungan antar tabel-tabel tersebut dapat dilihat dalam diagram ER (Entity Relationship) pada Gambar 3.

Dari relasi tabel tersebut, hubungan yang terjadi dalam proses sirkulasi yaitu antara anggota atau pemustaka dan koleksi perpustakaan. Setiap anggota perpustakaan memiliki ID Anggota yang akan digunakan untuk meminjam buku yang juga mempunyai ID Buku. ID ini berlaku juga dalam proses pengembalian koleksi. ID buku diperoleh dari tabel buku yang memuat identitas buku meliputi ID, judul, pengarang, penerbit, tahun terbit dan ISBN. Selanjutnya dalam tabel peminjaman dan pengembalian selain berisi ID baik anggota maupun buku, juga memuat tanggal pinjam dan tanggal kembali serta kode pinjam dan kode kembali. Kode ini yang akan menghubungkan ketika proses peminjaman dan pengembalian serta denda jika terjadi keterlambatan. Jadi relasi tabel tersebut merupakan suatu alur atau keterkaitan antara anggota dengan koleksi dalam proses sirkulasi peminjaman maupun pengembalian koleksi.

\section{Perancangan Desain Antar Muka}

Perancangandesain antar muka dalam sistem informasi perpustakaan sekolah merupakan perancangan menu antar muka yang berupa tampilan-tampilan layar yang digunakan untuk melakukan interaksi antara pustakawan dengan sistem informasi perpustakaan tersebut. Adapun rancangan antar muka pada sistem informasi perpustakaan sekolah dapat dilihat pada Gambar 4.

Analisis dan perancangan desain sistem yang dibahas dalam artikel ini hanya mencapai perancangan antar muka saja. Jadi artikel tidak membahas sampai dengan input data maupun output yang dihasilkan. 


\section{E. KESIMPULAN}

Berdasarkan pemaparan di atas dapat disimpulkan bahwa perancangan sistem informasi perpustakaan sekolah didasarkan pada analisis kebutuhan dari perpustakaan sekolah yaitu untuk mengurangi kesulitankesulitan yang terjadi pada layanan perpustakaan. Rancangan sistem informasi perpustakaan sekolah dibuat lebih sederhana daripada perpustakaan lain yaitu berdasarkan pada layanan sirkulasi meliputi peminjaman dan pengembalian serta laporan denda. Sistem informasi perpustakaan sekolah ini dirancang dengan bahasa pemrograman phpMyAdmin dan basis data SQL. Tahapan yang dilakukan antara lain dengan memasukkan data koleksi, data anggota, cetak kartu anggota, cetak kartu bebas pustaka, transaksi peminjaman dan pengembalian hingga pelaporan-pelaporan data termasuk laporan denda. Perancangan yang dilakukan untuk membuat sistem informasi perpustakaan sekolah ini meliputi perancangan sistem hingga perancangan antar muka untuk memudahkan pengguna maupun pustakawan dalam mengelola perpustakaan sekolah. Diharapkan dengan adanya perancangan sistem yang sederhana, setiap perpustakaan sekolah dapat membuat sendiri sistem informasi untuk perpustakaan agar pelayanan semakin efektif dan efisien.

\section{DAFTAR PUSTAKA}

Azwar, M. (2015). Penerapan sistem otomasi di perpustakaan Fakultas Adab dan Humaniora UIN Alauddin Makassar. Jurnal Al-Kuttab, (2) $1.45-67$.

Bafadal, I. (2006).Pengelolaan perpustakaan sekolah. Yogyakarta: Bumi Aksara. 5.

Dana, T., Samosir, D. H., \& Widiyasa, I. M. (2015, June). Pengembangan digital library Perpustakaan Universitas Atmajaya Yogyakarta. Seminar Nasional Informatika (SEMNASIF), 1, (5). 260-263.
Darmono, A. (2001). Manajemen dan tata kerja perpustakaan sekolah: konsep dasar dan aplikasinya. Jakarta: Kencana. 2.

Jogiyanto, H. M. (2000). Sistem informasi berbasis komputer : konsep dasar dan komponen. Yogyakarta: BPFE.. 3-4.

Kadir, A. (2009). Pengenalan Sistem Informasi. Yogyakarta: Andi. 5.

Ladjamudin, A. B. (2013). Analisis dan desain sistem informasi. Yogyakarta: Graha Ilmu. 8.

Lasa, H. S. (2009). Kamus kepustakawanan Indonesia. Yogyakarta: Pustaka Book Publisher. 315.

Nugraha, F. (2014). Analisa dan Perancangan Sistem Informasi Perpustakaan. Simetris: Jurnal Teknik Mesin, Elektro dan Ilmu Komputer, 5(1), 27-32.

Paryati\& Yosef, M. K. A. (2008). Sistem Informasi. Yogyakarta: Ardana Media.

Rahmawati, N. H. (2015). Upgrading sistem informasi Pusat Perpustakaan IAIN Surakarta: dari Sistem Perpustakaan (Siprus) ke Library System (Libsys). LIBRARIA: Jurnal Perpustakaan, 3(2), 247-264.

Susilowati, E. B., \& Purnama, B. E. (2017). Analisis dan perancangan sistem informasi pasien Rumah Sakit Umum Nirmala Suri Sukoharjo. Speed-Sentra Penelitian Engineering dan Edukasi, 3(4). 10-17.

Taufiq, R. (2013). Sistem informasi manajemen: konsep dasar, analisis dan metode pengembangan. Yogyakarta: Graha Ilmu. 3.

Yanti, F., Huda, Y., \& Hadi, A. (2014). Perancangan sistem informasi perpustakaan berbasis web dan SMS Gateway di SMA Negeri 3 Padang. Jurnal Vokasional Teknik Vokasional Teknik Elektronika \& Informatika, (2)1.1-14 


\section{DAFTAR GAMBAR}

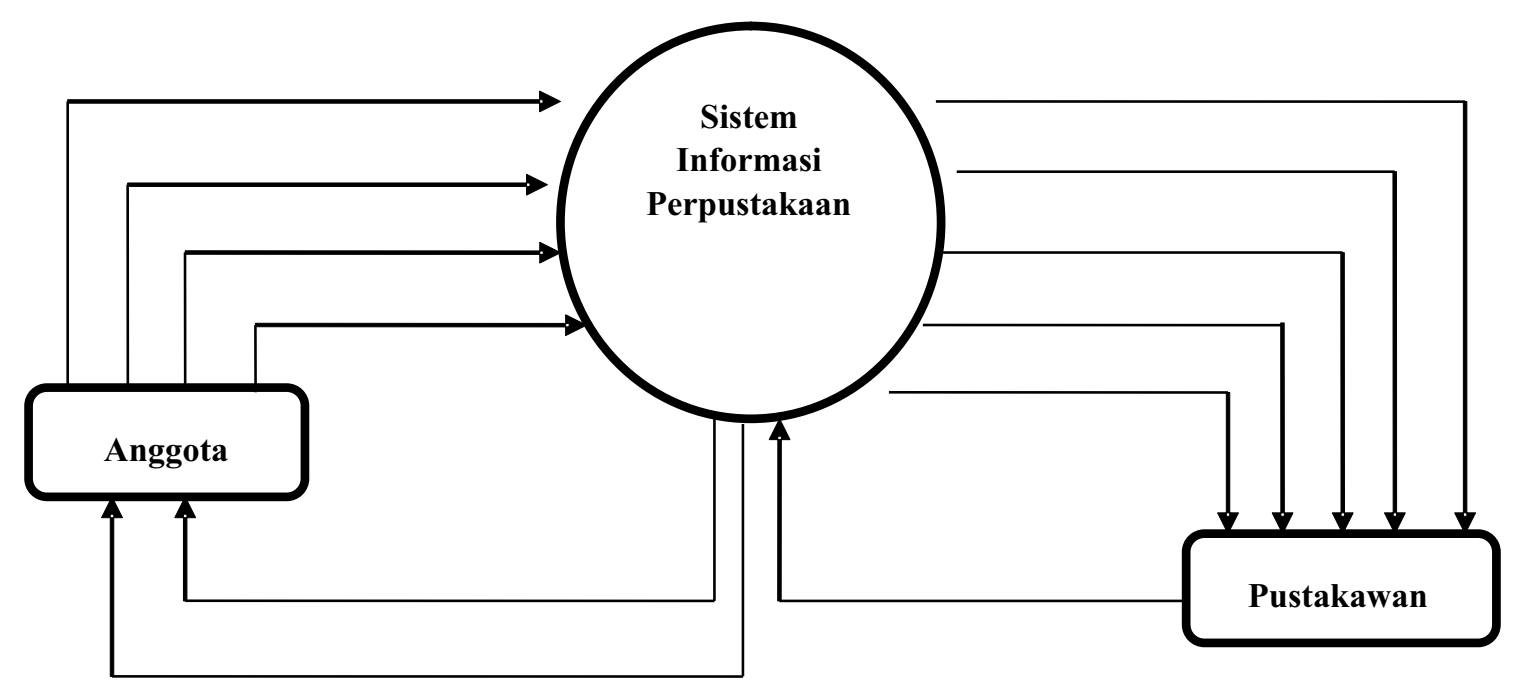

Gambar 1. Diagram Konteks

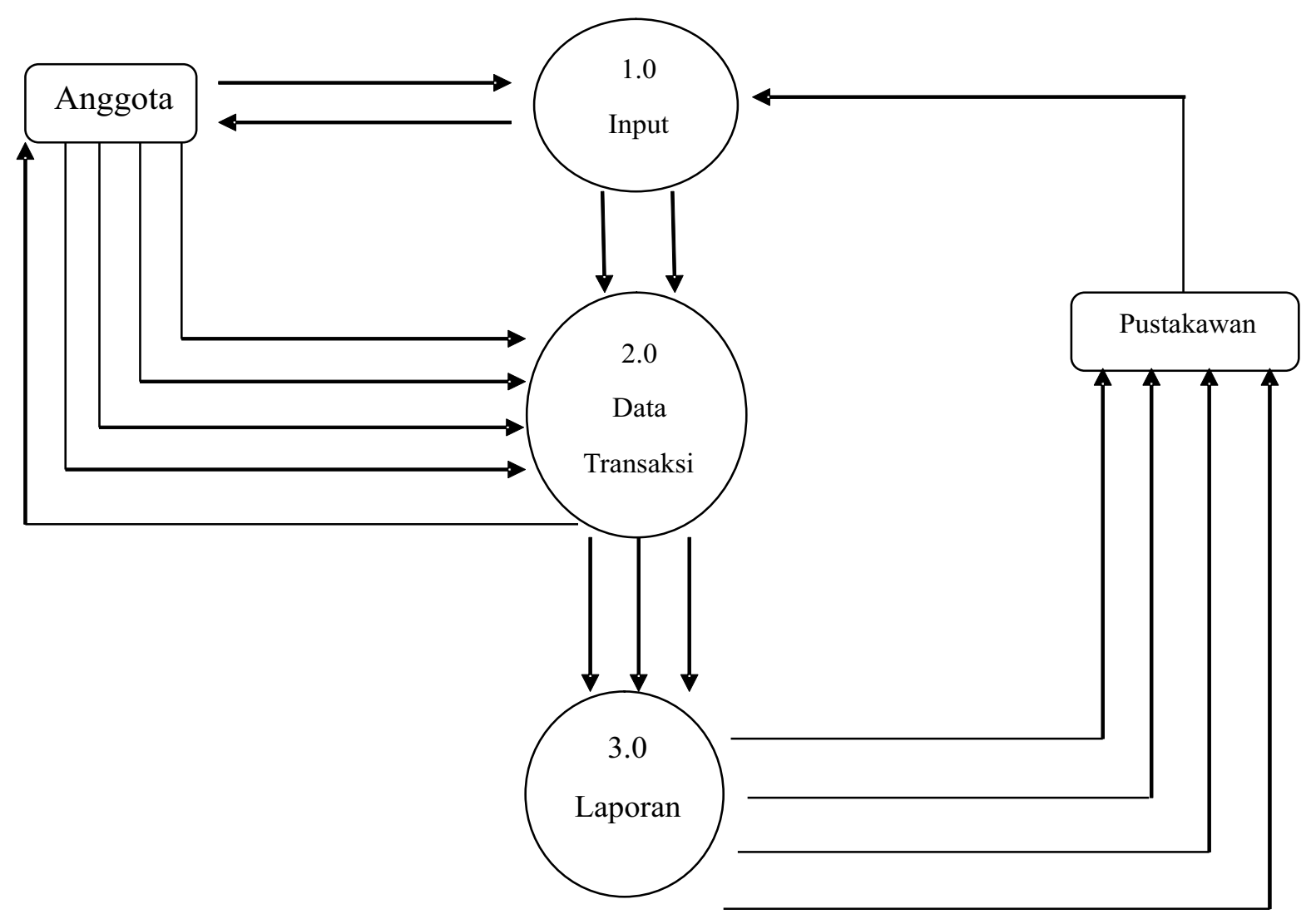

Gambar 2. Data Flow Diagram(DFD) Level-0 Sistem Informasi Perpustakaan Sekolah 


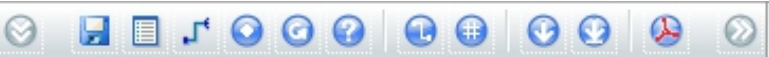

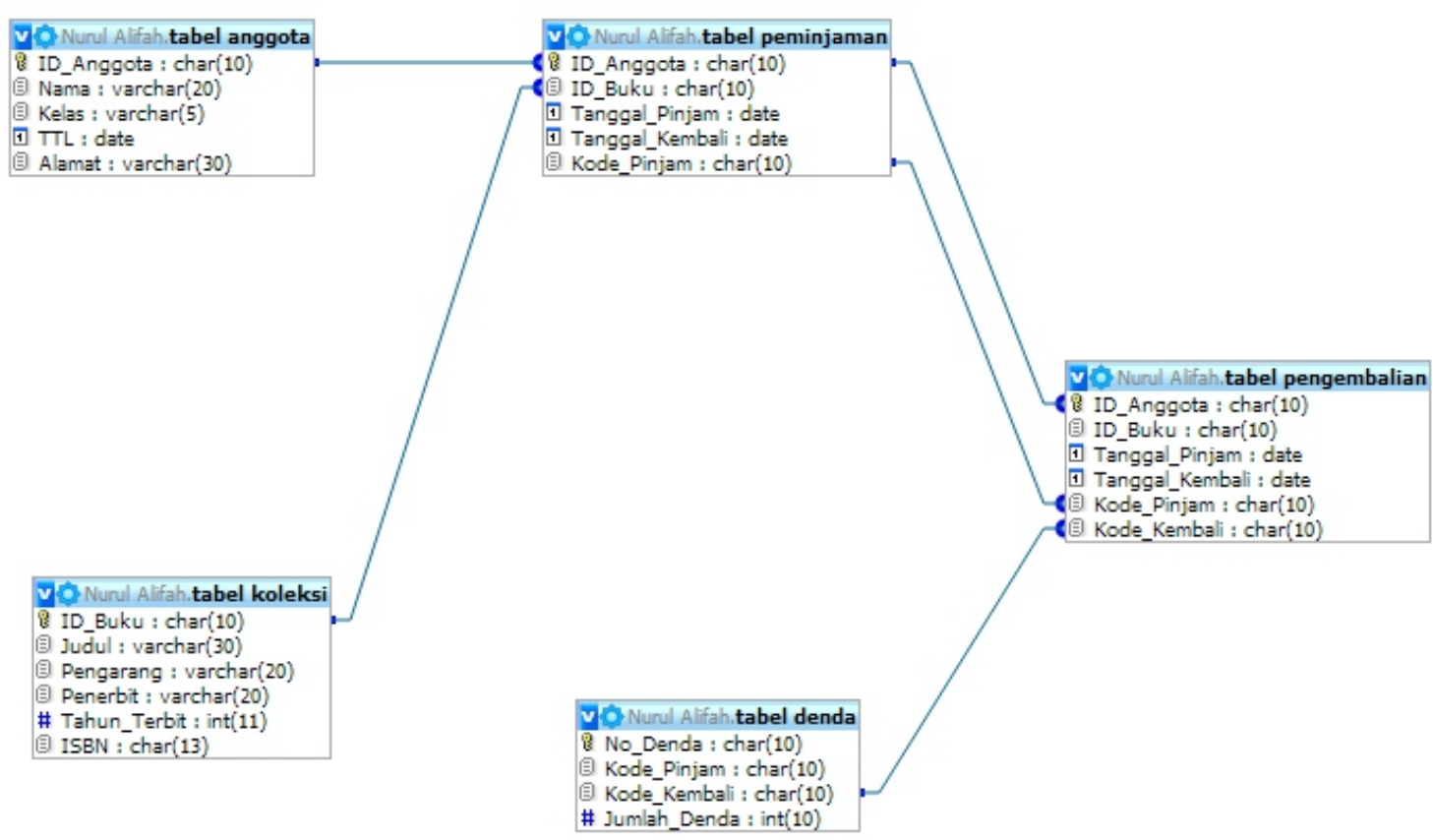

Gambar 3. Rancangan diagram ER dalam phpMyAdmin

\begin{tabular}{|c|c|c|c|c|}
\hline Beranda & Anggota & Koleksi & Transaksi & Pelaporan \\
\hline $\begin{array}{l}\text { Logout } \\
\text { Exit }\end{array}$ & $\begin{array}{l}\text { Tambah anggota } \\
\text { Hapus anggota } \\
\text { Edit anggota } \\
\text { Cetak kartu anggota }\end{array}$ & $\begin{array}{l}\text { Tambah koleksi } \\
\text { Hapus koleksi } \\
\text { Edit koleksi } \\
\text { Cetak barcode label } \\
\text { koleksi }\end{array}$ & $\begin{array}{l}\text { Peminjaman } \\
\text { Pengembalian }\end{array}$ & $\begin{array}{l}\text { Laporan } \\
\text { peminjaman } \\
\text { Laporan } \\
\text { pengembalian } \\
\text { Laporan denda }\end{array}$ \\
\hline \multicolumn{5}{|c|}{ Sistem Informasi Perpustakaan Sekolah } \\
\hline
\end{tabular}

Gambar 4. Flowchart antar muka 
DAFTAR TABEL

Tabel 1. Rancangan Struktur Tabel Anggota

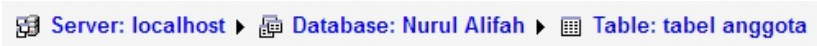

\begin{tabular}{|c|c|c|c|c|c|c|c|c|c|c|c|c|c|}
\hline \multicolumn{2}{|c|}{ 闻Browse } & Structure & Search & \multirow{2}{*}{$\frac{\text { Attributes }}{\text { Alnsert }}$} & \multicolumn{2}{|c|}{ 輩Export } & 䘓Import & \multicolumn{2}{|c|}{ OFerations } & \multicolumn{2}{|c|}{ 圌Empty } & \multicolumn{2}{|c|}{ Drop } \\
\hline & Field & Type & Collation & & Null & Default & Extra & & & ction & & & \\
\hline 回 & ID_Anggota & $\operatorname{char}(10)$ & latin1_general_ci & & No & None & & 畨 & $x$ & 栭 & 圈 & 夙 & 粗 \\
\hline 回 & Nama & $\operatorname{varchar}(20)$ & latin1_general_ci & & No & None & & 橉 & $x$ & 䦗 & 圆 & 咸 & 圆 \\
\hline$\square$ & Kelas & varchar(5) & latin1_general_ci & & No & None & & 闻 & $x$ & 㵒 & 圆 & 蕆 & 粵 \\
\hline 回 & TTL & date & & & No & None & & 閳 & $x$ & 橉 & 园 & 咸 & TT \\
\hline$\square$ & Alamat & $\operatorname{varchar}(30)$ & latin1_general_ci & & No & None & & 闻 & $x$ & 俨 & 圆 & 猲 & 粗 \\
\hline$\uparrow$ & Check All & check All & th selected: 瘀 & & 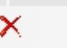 & 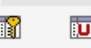 & 目 & 曾 & & & & & \\
\hline
\end{tabular}

Tabel 2. Rancangan Struktur Tabel Koleksi

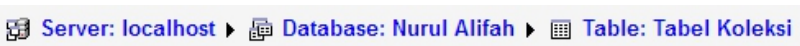

\begin{tabular}{|c|c|c|c|c|c|c|c|c|c|c|c|c|c|c|}
\hline \multicolumn{2}{|c|}{ 国Browse } & Structure & \multirow{2}{*}{$\begin{array}{l}\text { Search } \\
\text { Collation }\end{array}$} & \multirow{2}{*}{$\frac{\text { zitinsert }}{\text { Attributes }}$} & 㬝Export & \multicolumn{2}{|c|}{$\mathrm{t}$ 㬝 Import } & \multicolumn{3}{|c|}{ g:Operations } & \multicolumn{2}{|c|}{ 䣿Empty } & \multicolumn{2}{|c|}{ Drop } \\
\hline & Field & Type & & & Null & Default & Extra & & & & Action & & & \\
\hline 回 & ID_Buku & $\operatorname{char}(10)$ & latin1_general_ci & & No & None & & 粗 & $\theta$ & $x$ & 貣 & 圆 & 四 & 粗 \\
\hline 回 & Judul & $\operatorname{varchar}(30)$ & latin1_general_ci & & No & None & & 瞿 & $\theta$ & $x$ & 㵒 & 圆 & 凮 & 粗 \\
\hline 口 & Pengarang & $\operatorname{varchar}(20)$ & latin1_general_ci & & No & None & & 貫 & 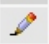 & $x$ & 㵒 & 圆 & 图 & 粗 \\
\hline$\square$ & Penerbit & $\operatorname{varchar}(20)$ & latin1_general_ci & & No & None & & 眯 & $\theta$ & $x$ & 哑 & 圆 & 䦑 & 粗 \\
\hline$\square$ & Tahun_Terbit & $\operatorname{int}(11)$ & & & No & None & & 圊 & 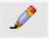 & $x$ & 圆通 & 闰 & 咸 & 粗 \\
\hline$\square$ & ISBN & char(13) & latin1_general_ci & & No & None & & 粗 & $\theta$ & $x$ & 凰烈 & 圆 & 四 & 泟 \\
\hline
\end{tabular}

Tabel 3. Rancangan Struktur Tabel Peminjaman

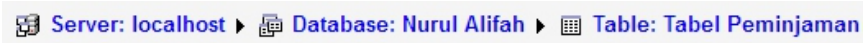

\begin{tabular}{|c|c|c|c|c|c|c|c|c|c|c|c|c|c|c|}
\hline 謴Browse & \multirow{2}{*}{$\begin{array}{l}\text { Structure } \\
\text { Field }\end{array}$} & \multirow{2}{*}{$\frac{{ }_{5, R}^{R} \text { SQL }}{\text { Type }}$} & \multirow{2}{*}{$\frac{\rho \text { Search }}{\text { Collation }}$} & thinsert & 鉒Export & \multicolumn{2}{|c|}{ 桼IImport } & \multicolumn{3}{|c|}{ agoperations } & \multirow{2}{*}{\multicolumn{2}{|c|}{ 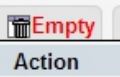 }} & \multicolumn{2}{|c|}{ Drop } \\
\hline & & & & Attributes & Null & Default & Extra & & & & & & & \\
\hline$\square$ & ID_Anggota & $\operatorname{char}(10)$ & latin1_general_ci & & No & None & & 瞿 & $\theta$ & $x$ & 閴 & 闹 & 夙 & 囯 \\
\hline$\square$ & ID_Buku & $\operatorname{char}(10)$ & latin1_general_ci & & No & None & & 雷 & $\theta$ & $x$ & 䦗 & 圆 & 四 & 专 \\
\hline$\square$ & Tanggal_Pinjam & date & & & No & None & & 愳 & 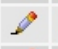 & $x$ & 酉 & 司 & 构 & 葍 \\
\hline$\square$ & Tanggal_Kembali & date & & & No & None & & 眮 & 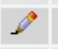 & $x$ & 同斯 & 可 & 构 & TT \\
\hline$\square$ & Kode_Pinjam & $\operatorname{char}(10)$ & latin1_general_ci & & No & None & & 闻 & $\theta$ & $x$ & 賏 & 可 & 杨 & 嘈 \\
\hline$\uparrow$ & Check All / Un & All Wit & elected: 嘈 & $x$ & 鬧 & 㐭 & 䅉 & & & & & & & \\
\hline
\end{tabular}

Tabel 4. Rancangan Struktur Tabel Pengembalian

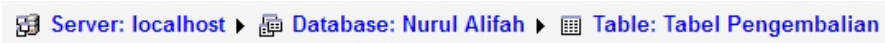

\begin{tabular}{|c|c|c|c|c|c|c|c|c|c|c|c|c|c|c|}
\hline 貫Browse & \multirow{2}{*}{$\begin{array}{l}\text { Structure } \\
\text { Field }\end{array}$} & \multirow{2}{*}{ 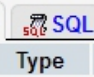 } & \multirow{2}{*}{$\frac{\text { Search }}{\text { Collation }}$} & Żtinsert & 聆Export & \multicolumn{2}{|c|}{ 重IImport \& } & \multicolumn{3}{|c|}{ ZूOperations } & \multicolumn{2}{|c|}{ Iili Empty } & \multicolumn{2}{|c|}{ Drop } \\
\hline & & & & Attributes & Null & Default & Extra & & & & Action & & & \\
\hline$\square$ & ID_Anggota & $\operatorname{char}(10)$ & latin1_general_ci & & No & None & & 闻 & 8 & $x$ & 夙 & 可 & 係 & 葍 \\
\hline$\square$ & ID_Buku & $\operatorname{char}(10)$ & latin1_general_ci & & No & None & & 䩀 & $\theta$ & $x$ & 俨 & 间 & 凬 & 专 \\
\hline$\square$ & Tanggal_Pinjam & date & & & No & None & & 瞋 & 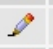 & $x$ & 闐 & 闹 & 凬 & 粗 \\
\hline$\square$ & Tanggal_Kembali & date & & & No & None & & 霜 & 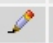 & $x$ & 閣 & 圈 & 係 & 賁 \\
\hline$\square$ & Kode_Pinjam & $\operatorname{char}(10)$ & latin1_general_ci & & No & None & & 闻 & 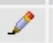 & $x$ & 圆 & 可 & 係 & 粵 \\
\hline$\square$ & Kode_Kembali & $\operatorname{char}(10)$ & latin1_general_ci & & No & None & & 䡳 & $\theta$ & $x$ & 閳 & 闰 & 四 & 囯 \\
\hline
\end{tabular}

Tabel 5. Rancangan Struktur Tabel Denda

息 Server: localhost ・恿 Database: Nurul Alifah • 国 Table: Tabel Denda

\begin{tabular}{|c|c|c|c|c|c|c|c|c|c|c|c|c|c|c|}
\hline 眶Browse & Structure & ${ }_{5, \mathrm{R}} \mathrm{SQL}$ & Search & \multirow{2}{*}{$\frac{F}{\text { Attributes }}$} & 需Export & \multicolumn{2}{|c|}{ t 睡IImport } & \multicolumn{3}{|c|}{ agoperations } & \multicolumn{2}{|c|}{ 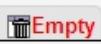 } & \multicolumn{2}{|c|}{ Xiop } \\
\hline & Field & Type & Collation & & Null & Default & Extra & & & & ction & & & \\
\hline$\square$ & No_Denda & $\operatorname{char}(10)$ & latin1_general_ci & & No & None & & 闻 & 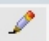 & $x$ & 唒通 & 圆 & 四 & 粗 \\
\hline$\square$ & Kode_Pinjam & $\operatorname{char}(10)$ & latin1_general_ci & & No & None & & 闻 & $\theta$ & $x$ & 䊧 & 圆 & 厚 & 汿 \\
\hline$\square$ & Kode_Kembali & $\operatorname{char}(10)$ & latin1_general_ci & & No & None & & 䁬 & 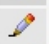 & $x$ & 閆 & 圆 & 四 & 捆 \\
\hline$\square$ & Jumlah_Denda & $\operatorname{int}(10)$ & & & No & None & & 貫 & $\theta$ & $x$ & 橉 & 闹 & 咸 & 圆 \\
\hline$\uparrow$ & Check All / U & & bolot & & & 园 & 嚴 & & & & & & & \\
\hline
\end{tabular}

